\title{
Um lugar para morrer: experiências de morte domiciliar
}

\author{
A place to die: experiences of home death \\ AZEVEDO, Daniel Lima. O melhor lugar para morrer. Curitiba: \\ Appris, 2020. $160 \mathrm{p}$.
}

"Quem disse que eu me mudei? Não importa que a tenham demolido, a gente continua morando na velha casa em que nasceu."

(Quintana, 1986, p. 760)
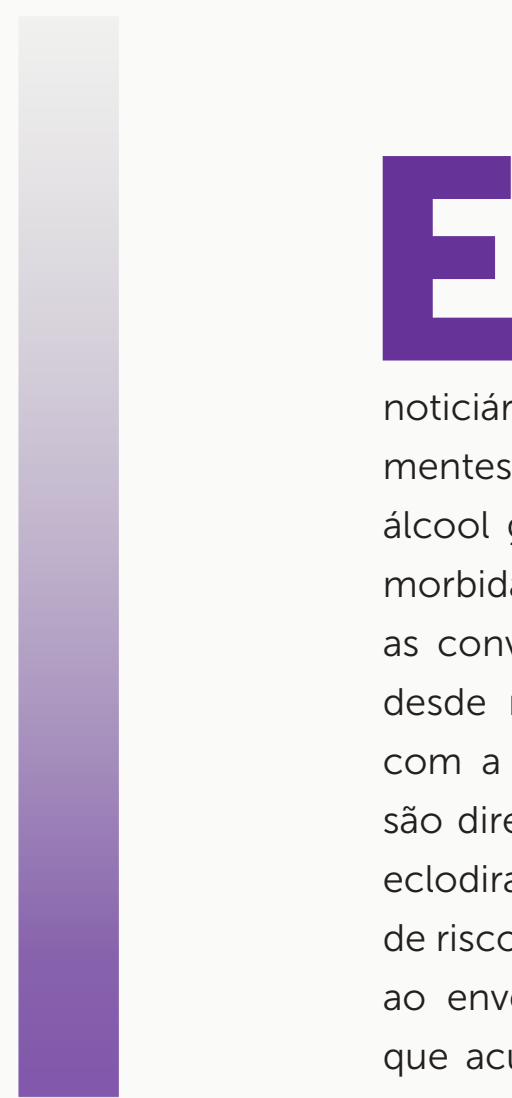

nquanto inicio a elaboração desta resenha, recebo a notícia da morte de metade dos "idosos" com demência em Roterdã, na Holanda. Essa é apenas uma, dentre tantas outras notícias que pululam nos noticiários e redes sociais sobre a pandemia que afeta corpos e mentes nesse abril de 2020. Isolamento social, vírus, infecção, álcool gel, álcool 70, quarentena, remédios, CTI, EPI, morte, morbidade, são algumas palavras e siglas acionadas em todas as conversas empreendidas nas últimas semanas, ao menos desde março de 2020. Todos, em algum momento, lidam com a temática da morte, mas são os mais velhos os que são diretamente associados ao processo do morrer. Estigmas eclodiram no espectro das narrativas sobre o principal "grupo de risco". Morre-se mais por acumular comorbidades inerentes ao envelhecer. São apontados como detentores de corpos que acumulam falências, perdas e incapacidades. Em outros

* Doutora em Ciências Sociais pela Universidade do Estado do Rio de Janeiro (UERJ). Professora do curso de Ciências Sociais e do Programa de Pós-Graduação em Memória Social da Universidade Federal do Estado do Rio de Janeiro (UNIRIO). CV: http://lattes.cnpq.br/6818727272836757 
termos, significa que já estão "mais pra lá, do que pra cá", "só vão morrer 5\%", como declamam os poetas da necropolítica (Mbembe, 2018).

Ler o livro de Daniel Lima Azevedo, "O melhor lugar para morrer", no contexto da pandemia que tem exposto cruamente estigmas e desigualdades sociais, só não é mais difícil por apresentar uma escrita lúcida, direta e sensível, capaz de (re)mexer em emoções profundas. Médico geriatra, profissional voltado ao tratamento daqueles que estão em etapa da vida considerada crítica, possui experiência significativa na gestão da morte de pacientes em domicílio. Sentiu despertar nessas relações temáticas concernentes ao debate das Ciências Sociais, que o levaram a investir em uma literatura específica que as alicerçasse. Assim, o livro foi desenvolvido no âmbito de Pós-Graduação em Saúde Coletiva no IESC/UFRJ, como fruto de pesquisa de dissertação de mestrado, compondo um material expressivo de experiências, profissional e acadêmica do autor, e de trajetórias das entrevistadas.

Qual o lugar mais adequado? Para quem? Em um trecho, o autor observa que já se questionou sobre a morte domiciliar, será que a casa/o lar é, "de fato, o ambiente mais adequado para assegurar as demandas da pessoa doente durante o processo de morrer" ( $p$. 25)? Morrer em casa ou no hospital parece ser o dilema enfrentado majoritariamente por quem pode escolher. O ponto chave é o debate sobre autonomia. O hospital é a técnica, a crença na ciência, na vida e em sua extensão. É também um espaço considerado ascético, destituído de emoções, impessoal. O ambiente da casa, do lar, é entendido como refúgio, lugar da intimidade, do aconchego. No entanto, os relatos evidenciam que também podem se tornar locais desfigurados, pelos impactos das mudanças necessárias à assistência domiciliar, que requer alterações severas na organização dos ambientes e das famílias. A sala pode se tornar quarto, objetos precisam ser retirados de seus locais usuais, pessoas desconhecidas, em particular profissionais de saúde, que se revezam nos cuidados, passam a transitar por espaços anteriormente considerados privados. A própria privacidade corporal pode ser constantemente invadida, ainda que se pretenda estar sob a proteção do lar, porque "a casa pode deixar de ser o ambiente em que o enfermo encontra acolhimento e segurança" (p. 126), de modo a se tornar tão estranha e desconfortável quanto o ambiente hospitalar, regido por rotinas rigorosas.

Com tais indagações o pesquisador constrói o argumento constante nos sete capítulos que ordenam o olhar dos leitores. Apresenta a construção social dos conceitos velhice e morte, com base nas perspectivas histórica e antropológica, no Ocidente. Neste aspecto, há tanto um debate em torno da ampliação da expectativa do tempo de vida, devido ao avanço de tecnologias (medicamentos, vacinas, equipamentos), quanto das consequências do envelhecimento populacional, que requer políticas públicas efetivas de proteção social (como previdência social). Outros fatores também estão presentes nesse complexo processo de "protagonismo" da velhice, numa sociedade que reifica os corpos jovens. A velhice, por vezes compreendida como etapa final da vida, também pode ser tida como "melhor idade" ou, ainda, como ameaça econômica.

As implicações nas decisões sobre o melhor local para falecer são aqui problematizadas, considerando que a morte domiciliar antagoniza, em certo sentido, com a morte hospitalar. Morrer em casa significaria conferir dignidade relacional e afetiva ao moribundo, enquanto 
morrer no hospital não contaria com tal possibilidade. A ideia principal do livro é "confrontar" a proposta da morte domiciliar com as percepções de "familiares que acompanharam o processo de morrer de idosos em casa".

A análise foi construída a partir de seis entrevistas com familiares-cuidadoras. O cuidado tem gênero. Filhas, netas e esposas são as responsáveis pela atenção ao processo de morrer. Estas assumem o controle de corpos e decisões ou, ao menos, assumem o papel de mediação entre moribundo, médicos, instituições, parentes e documentos, diante das limitações inevitáveis dessa fase da vida. O autor adere à noção de processo para compreender a complexidade de situações, atores e negociações necessárias ao empreendimento do "morrer em casa" na sociedade contemporânea. Esta é importante para o entendimento de que existem muitos fatores a serem considerados, que podem extrapolar os próprios limites da pesquisa. Por este motivo, reconhecê-los e delimitar o recorte é condição necessária para validar a argumentação.

O perfil dessas mulheres aponta que se preocupam em interagir, cuidar e respeitar as decisões do ente querido em seu momento final. Podem acessar uma rede profissional de cuidado. Prezam pela autonomia. Possuem minimamente recursos materiais para a realização do desejo do moribundo. O texto não explicita variáveis relevantes, como raça/etnia e classe social. Embora o autor deixe claro que não tem a intenção de esgotar a discussão e que se trata de pesquisa qualitativa de pequeno porte, com poucos informantes, ao adotar como ponto de discussão determinadas categorias, como autonomia e escolha, seria valiosa uma reflexão em torno de tais marcadores sociais, para um entendimento das concepções das entrevistadas sobre casa, família, papeis sociais, medicalização, entre outros. As biopolíticas sobre os corpos impactam de distintas maneiras os grupos sociais, inclusive os idosos, que podem ser classificados como "vidas não passíveis de luto" (Butler, 2015).

As concepções de morte e cuidado interagem com as de dignidade e possibilidades. A "morte digna" tangencia os limites do cuidado possível, em face de fatores econômicos, sociais, culturais e emocionais. Está associada a quem cuida, à família, aos laços que se tornam evidentes e fortalecidos, ainda que possam também apresentar conflitos e tensões. A morte é coletiva, não é simplesmente um evento biológico individual. A morte social não está diretamente em compasso com a morte biológica. A primeira pode ocorrer muito antes, pelos fatores mencionados. Doenças também podem produzir essa dissociação: idosos com algum tipo de demência consistem em exemplos, como em um relato destacado pelo autor, assim como podem ser estabelecidas devido a desigualdades sociais, racismo, homofobia, misoginia. O direito ao luto não se refere, assim, àqueles que nunca foram ou, em algum momento, deixaram de ser reconhecidos socialmente como pessoas (Mauss, 2003; Duarte, 2003).

Situações enfocadas na pesquisa possibilitaram problematizar princípios que baseiam o entendimento de que "a casa" é o melhor lugar para morrer, em contraste ao aparato médico hospitalar. Todavia, argumenta que a "boa morte" nem sempre se vincula à casa, pois ela também pode significar espaço de conflito, tensões e disputas, envolvendo os distintos personagens que integram a dinâmica do cuidado. Assim, pode não diferir do que ocorreria em ambiente hospitalar, uma vez que, onde quer que o moribundo seja cuidado, predominam 
tecnologias médicas e jurídicas, valores familiares e relações de poder.

A relação entre gênero e geração com o morrer merece atenção para novas pesquisas. Destacam-se os relatos nos quais essas mulheres evidenciam ambiguidade em torno da morte domiciliar. Ainda que não demonstrem arrependimento pelo acompanhamento de seus familiares, questionam a escolha, quando elas próprias alcançarem essa etapa da vida. Receber afeto ou poupar os filhos? A decisão deve ser deles, argumenta uma entrevistada. No entanto, questiona: terão capacidade para tamanha responsabilidade? Outras indagações emergem no decorrer da leitura e abrem possibilidades de aprofundamento do diálogo entre medicina e ciências sociais. Tal exercício é exemplarmente realizado, embora Azevedo ressalte ser um neófito "no fazer" pesquisa qualitativa, em especial em seu viés antropológico. Apesar dessa avaliação, o autor conquista o objetivo de apresentar um texto consistente.

A obra "O melhor lugar para morrer", como referência para refletir sobre o cuidado no final da vida em casa, transmite essa complexidade e suscita lembranças de experiências particulares sobre mortes em família. Foi inevitável lembrar de situações ocorridas em minha rede familiar, que evidenciavam limites, frustrações, desapego, falta de estrutura. Para além de questões teóricas importantes, esses momentos são de grande valor na leitura, por conduzir a uma ativação de memórias, conformando uma intimidade compartilhada com as experiências descritas. Assim, a narrativa torna-se ainda mais sensível, por acionar a experiência de Azevedo, concomitantemente à realização da pesquisa, no acompanhamento do final da vida e morte de sua avó Berenice, no apartamento em que viveu a maior parte de sua vida. Decisões difíceis são tomadas a cada situação que se impõe. São, também, ressignificadas de acordo com as posições ocupadas nas relações estabelecidas. Emoções e memórias se entrecruzam nos momentos finais, e se condensam na seguinte frase: "Estou fazendo tudo o que posso para você ficar confortável" (p. 142). Realizar o possível diante do inevitável é o que move aquilo que pode ser denominado como "cuidado".

O morrer em domicílio está envolto em diversas camadas. Uma se impõe pelo romantismo idealizado na casa e no indivíduo, que tem no vínculo com o passado e com a relação entre gerações seu suporte primordial. Outra está associada ao respeito à autonomia, à expressão da escolha por morrer em casa, o que muitas vezes é rememorada pelo(s) responsável(eis) pelo cuidado, diante do declínio físico e mental do enfermo, incapaz de externalizar seu desejo. Inseguranças ocorrem em torno das decisões, emerge um movimento de conduzir o moribundo ao hospital, diante da dificuldade em lidar com o fim da vida. $\bigcirc$ livro apresenta essas situações e contribui para o debate crítico sobre o "morrer bem" na contemporaneidade, deixando em aberto, entre outras perguntas: quem é o protagonista nesse processo?, como ser "protagonista" até o final?

\section{Referências Bibliográficas}

AZEVEDO, Daniel Lima. O melhor lugar para morrer. Curitiba: Appris, 2020. 160 p. 
BUTLER, Judith. Quadros de guerra: quando a vida é passível de luto. Civilização Brasileira: Rio de Janeiro, 2015. 288 p.

DUARTE, Luiz Fernando Dias. Indivíduo e pessoa na experiência da saúde e da doença. Ciência \& Saúde Coletiva. Rio de Janeiro, v. 8, n. 1, p. 173-183, 2003.

MAUSS, Marcel. Uma categoria do espírito humano: a noção de pessoa, a noção de eu. In: MAUSS, Marcel. Sociologia e antropologia. São Paulo: Cosac Naify, 2003. p. 367-398.

MBEMBE, Achille. Necropolítica. São Paulo: N-1 edições, 2018. 80 p.

QUINTANA, Mário. Quem disse que eu me mudei? In: QUINTANA, Mário. Preparativos de viagem. Rio de Janeiro: Globo, 1986. 760 p.

Recebida em: 15 de abril de 2020

Aprovada em: 30 de maio de 2020 